\title{
Aldosterone-Producing Adrenal Cortical Cancer: A Case Report and Analysis of Steroidogenic Enzymes in the Tumor
}

\author{
MASAAKI MORIOKA, YOJI FURUKAWA, TATSUYA KOBAYASHI, \\ HIROYOSHI TANAKA, YOZO OHASHI*, AND TIE-XIONG JIN* \\ Department of Urology, Kawasaki Medical School, Kurashiki 701-01, and \\ *Department of Urology, Kochi Medical School, Nankoku 783, Japan
}

\begin{abstract}
A case of hyperaldosteronism caused by adrenal cortical cancer observed in a 32-year-old man was reported. The patient showed marked hypertension and hypokalemia, but neither obesity nor hyperglycemia was observed. Endocrine studies revealed hyperaldosteronism and concurrent excessive secretion of cortisol, but diurnal rhythms of plasma ACTH and cortisol were normal. Imaging studies revealed a large left adrenal mass, and the positive accumulation of radiolabelled material by adrenal scintigraphy was observed both in the tumor and the contralateral adrenal gland. The removed tumor was predominantly composed of dark compact cells with marked nuclear pleomorphism, and mitotic figures and sinusoidal invasion were also observed. The analysis of steroidogenic enzyme activities revealed that the activity of aldosterone-synthesizing enzyme (P-450aldo) which was usually undetectable in normal adrenal tissues and adenomas other than aldosterone-producing adenoma (APA) was detectable as one-third of that of APA. Although activities of other enzymes were reduced, the expression of P-450aldo activity was considered to be the specific character of this cancer.
\end{abstract}

Key words: Adrenocortical cancer, Hyperaldosteronism, Hypercortisolism

(Endocrine Journal 44: 547-552, 1997)

\begin{abstract}
ADRENOCORTICAL cancer is a rare disease which is observed in only 0.02 to $0.2 \%$ of all cancer deaths, and approximately $60 \%$ of patients show excessive production of steroid hormones [1-4]. Because steroid production by adrenal cancer is usually weaker than that of cortical adenomas such as aldosterone-producing adenoma (APA), adrenal cancer had been discovered as a large abdominal mass and/or as a metastasizing cancer [3]. But due to the development of imaging techniques, the number of incidentally found adrenal tumors has been increasing, and the frequency of detection of adrenocortical carcinomas has increased lately [5]. We report a case of adrenal cortical cancer which
\end{abstract}

Received: February 26, 1997

Accepted: May 29, 1997

Correspondence to: Dr. Masaaki MORIOKA, Department of Urology, Kawasaki Medical School, 577 Matsushima, Kurashiki 701-01, Japan produced both aldosterone and cortisol, and the character of the steroidogenesis of the tumor was examined.

\section{Case Report}

A thirty-two-year-old man was found to have hypertension $(220 / 120 \mathrm{mmHg})$ when he consulted a home doctor for medical attention for upper respiratory distress. He had sometimes experienced mild occipital pain, but never experienced muscle weakness in his clinical history. Routine laboratory tests which consisted of a complete blood count, serum electrolytes and creatinine, liver function test, serum cholesterol, serum proteinogram and complete urinalysis were normal except for hypokalemia $(2.7 \mathrm{mEq} / \mathrm{L})$. He was referred to our hospital for further investigations in March, 1996. His blood pressure 
Table 1. Endocrine data I

\begin{tabular}{|c|c|c|c|c|}
\hline \multicolumn{3}{|l|}{ Plasma level of } & \multicolumn{2}{|c|}{ Normal range } \\
\hline Progesterone & \multicolumn{2}{|c|}{0.78} & \multicolumn{2}{|c|}{$017 \sim 0.67 \mathrm{ng} / \mathrm{ml}$} \\
\hline $17 \mathrm{OH}$-progesterone & \multicolumn{2}{|c|}{1.81} & \multicolumn{2}{|c|}{$0.35 \sim 2.0 \mathrm{ng} / \mathrm{ml}$} \\
\hline Androstenedione & \multicolumn{2}{|c|}{1.46} & \multicolumn{2}{|c|}{$0.82 \sim 1.85 \mathrm{ng} / \mathrm{ml}$} \\
\hline 11-deoxycorticosteror & \multicolumn{2}{|c|}{ e 0.16} & \multicolumn{2}{|c|}{$0.08 \sim 0.28 \mathrm{ng} / \mathrm{ml}$} \\
\hline Corticosterone & \multicolumn{2}{|c|}{3.42} & \multicolumn{2}{|c|}{$0.37 \sim 8.42 \mathrm{ng} / \mathrm{ml}$} \\
\hline Aldosterone & \multicolumn{2}{|c|}{24} & \multicolumn{2}{|c|}{$2 \sim 18 \mathrm{ng} / \mathrm{d} l$} \\
\hline Cortisol & \multicolumn{2}{|c|}{12.5} & \multicolumn{2}{|c|}{$4.5 \sim 16.2 \mu \mathrm{g} / \mathrm{d} l$} \\
\hline DHA-S & \multicolumn{2}{|c|}{1267} & \multicolumn{2}{|c|}{$1300 \sim 5600 \mathrm{ng} / \mathrm{ml}$} \\
\hline Testosterone & \multicolumn{2}{|c|}{544} & \multicolumn{2}{|c|}{$410 \sim 1100 \mathrm{ng} / \mathrm{d} l$} \\
\hline Plasma renin activity & \multicolumn{2}{|c|}{$<0.1 \sim 0.4$} & \multicolumn{2}{|c|}{$0.2 \sim 2.7 \mathrm{ng} / \mathrm{ml} / \mathrm{h}$} \\
\hline ACTH & \multicolumn{2}{|c|}{36.2} & \multicolumn{2}{|c|}{$7.4 \sim 55.7 \mathrm{pg} / \mathrm{ml}$} \\
\hline \multicolumn{5}{|l|}{ Urinary excretion of } \\
\hline Aldosterone & \multicolumn{2}{|c|}{$15.0 \sim 32.6$} & \multicolumn{2}{|c|}{$<7.5 \mu \mathrm{g} /$ day } \\
\hline $17 \mathrm{OHCS}$ & \multicolumn{2}{|c|}{$11.5 \sim 22.3$} & \multicolumn{2}{|c|}{$3.1 \sim 8.7 \mathrm{mg} /$ day } \\
\hline $17 \mathrm{KS}$ & \multicolumn{2}{|c|}{$6.7 \sim 6.9$} & \multicolumn{2}{|c|}{$4.2 \sim 12.4 \mathrm{mg} /$ day } \\
\hline Adrenaline & \multicolumn{2}{|c|}{$9.1 \sim 11.3$} & $<28$ & /day \\
\hline Noradrenaline & & 94.1 & $19 \sim 15$ & ug/day \\
\hline Dopamine & & 885 & $130 \sim 1$ & $0 \mu \mathrm{g} /$ day \\
\hline Diurnal rhythm & & & & \\
\hline Time (h) & 300 & 1200 & 1600 & 2300 \\
\hline PRA & .1 & 0.4 & $<0.1$ & 0.4 \\
\hline PAC & 4 & 17 & 20 & 18 \\
\hline Cortisol & 0.8 & 8.2 & 7.4 & 5.4 \\
\hline ACTH & 8.8 & 22.7 & 19.8 & 7.7 \\
\hline
\end{tabular}

DHA-S, dehydroepiandrosterone sulfate; PRA, plasma renin activity; PAC, plasma aldosterone concentration.

was $190 / 120 \mathrm{mmHg}$, and height and weight were $167 \mathrm{~cm}$ and $72 \mathrm{~kg}$, respectively. Endocrine studies revealed suppressed plasma renin activity (PRA) with a higher plasma aldosterone concentration (PAC), and the circadian rhythm of PAC was not detectable. Neither PAC nor PRA responded to stimulation by furosemide, captoril or dexamethasone (DXM), and urinary excretion of aldosterone was also increased. These data suggested the autonomous hypersecretion of aldosterone, but plasma levels of other mineralocorticoids such as corticosterone and 11deoxycorticosterone (DOC) were in the normal range. On the other hand, basal levels and circadian rhythms of plasma cortisol and ACTH were in the normal range, whereas excretions of urinary free cortisol (UFC) and 17hydroxycorticosteroids (17-OHCS) were increased. Moreover, the suppression of plasma cortisol level and excretion of UFC was incomplete even by the administration of high-dose DXM (8 mg). Plasma aldosterone and cortisol levels were increased
Table 2. Endocrine data II

Rapid ACTH stimulation test ( $0.25 \mathrm{mg}$ bolus injection)

\begin{tabular}{lcccc}
\hline & basal & $30 \mathrm{~min}$ & $60 \mathrm{~min}$ & $120 \mathrm{~min}$ \\
\hline Cortisol & 6.2 & 12.7 & 13.6 & 11.5 \\
PAC & 15 & 26 & 20 & 12 \\
\hline
\end{tabular}

Furosemide loading test ( $40 \mathrm{mg}$ bolus injection)

\begin{tabular}{lcc}
\hline & basal & $120 \mathrm{~min}$ \\
\hline PRA & 0.5 & 0.6 \\
PAC & 19 & 22 \\
\hline
\end{tabular}

Dexamethasone suppression test

\begin{tabular}{lccccc}
\hline Day & 1 & 2 & 3 & 4 & 5 \\
\hline DXM & $(-)$ & $1 \mathrm{mg}$ & $2 \mathrm{mg}$ & $8 \mathrm{mg}$ & $8 \mathrm{mg}$ \\
\hline ACTH & 38.8 & 3.0 & 3.23 & $<3.0$ & $<3.0$ \\
Cortisol & 10.8 & 4.5 & 3.2 & 4.2 & 4.6 \\
PAC & 24 & 34 & 20 & 18 & 22 \\
UFC & 374 & 105 & 69 & 137 & 74 \\
\hline
\end{tabular}

moderately by the bolus injection of ACTH $(0.25$ $\mathrm{mg}, 1-24$ ACTH). Plasma levels of progesterone, 17-hydroxyprogesterone, dehydroepiandrosterone sulfate (DHA-S) and testosterone were in the normal range. Urinary excretion of catecholamines and vanillyl mandelic acid (VMA) were also within normal limits (Tables 1 and 2). A CT scan showed a large inhomogeneous mass $(5 \times 6 \mathrm{~cm})$ in the left suprarenal area, and a moderate enhancement effect caused by the contrast medium was observed. The tumor was low intense compared to the liver on a T1-weighted magnetic resonance image (MRI), and low to isointense on a T2-weighted image (Fig. 1). An enhancing effect of the injection of gadolinium-diethylenetriamine pentaacetic acid (Gd-DTPA) was observed inhomogeneously. No lymph-node involvement or distant metastasis was identified. Adrenal scintigraphy with $6 \beta$ 131I-iodine 19 norcholesterol revealed the accumulation of radiolabelled material both in the tumor and the contralateral adrenal gland. In imaging studies this adrenal tumor was diagnosed as stage II adrenal cancer by the criteria of Sullivan [6]. Left adrenalectomy with lymph-node dissection was performed, and the removed tumor was $6 \times 5 \times 4$ $\mathrm{cm}$ in size and weighed $100 \mathrm{~g}$. The tumor was encapsulated with thin fibrous tissue and 


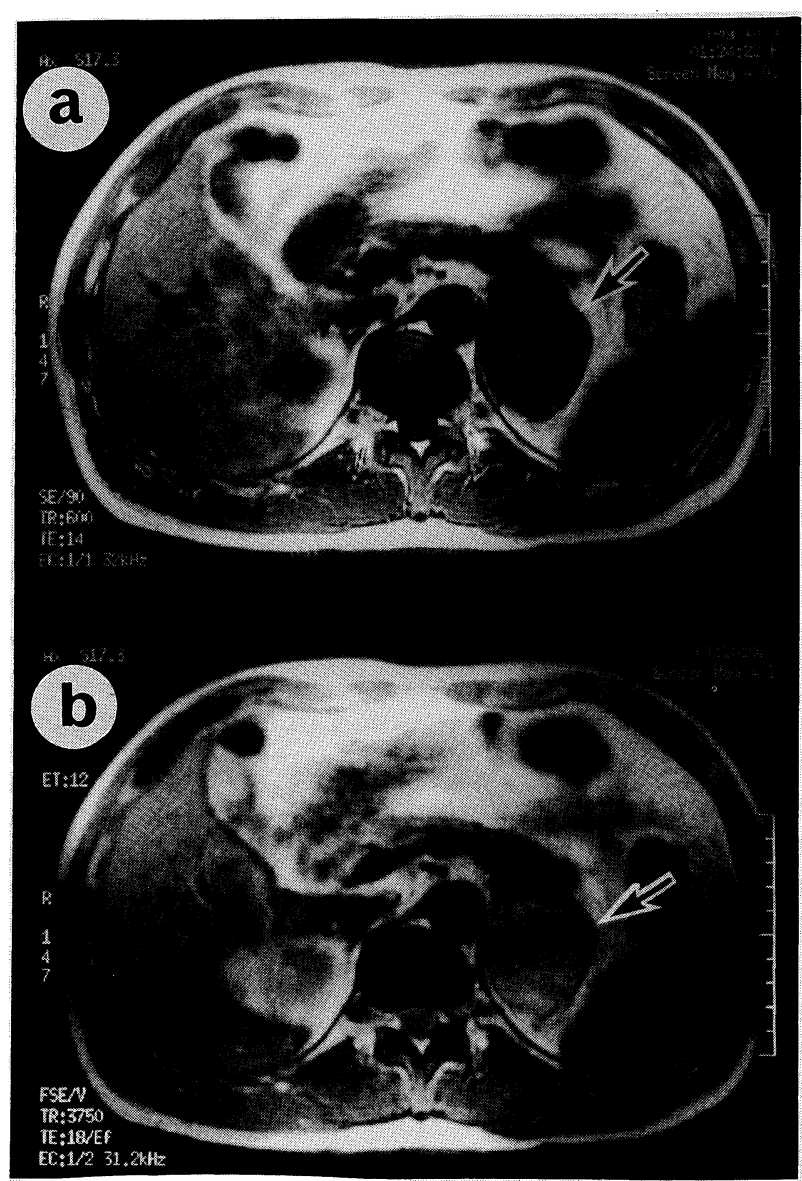

Fig. 1. Magnetic resonance imaging of the tumor. The tumor was hypointense on a T1-weighted image (a) and mixed low and isointense on a $\mathrm{T} 2$-weighted image (b). No extraadrenal invasion of adjacent organs or lymph-node involvement was observed.

compressed normal adrenal tissue was identified. The cut surface was dark brown to yellow colored without macroscopic necrosis or massive hemorrhage. The tumor was predominantly (more than $80 \%$ ) composed of dark compact cells with marked nuclear pleomorphism and a clear nucleolus. Tumor cells showed trabecular or alveolar arrangements, and although capsular invasion and lymph-node involvement were not observed, sinusoidal invasion was identified. Mitosis was fairly frequent (6 10/50 HPF) and multinucleated or giant cells were focally observed. The nuclear grade was diagnosed as grade II (Fig. 2). The non-neoplastic adrenal tissue showed the almost normal features, and no hyperplastic appearance was seen. These pathological features

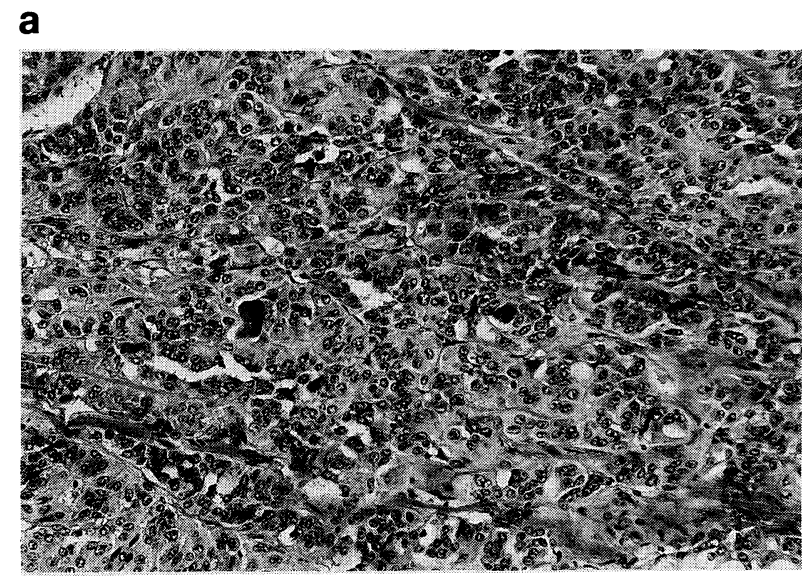

b

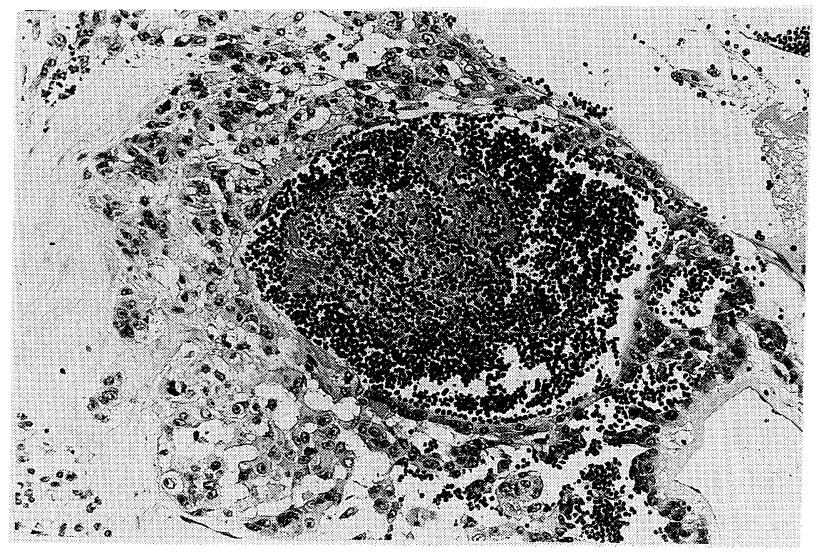

Fig. 2. Histopathological findings. The tumor was predominantly composed of dark compact cells with marked nuclear pleomorphism and a clear nucleolus. Cancer cells showed trabecular or alveolar arrangements, and mitotic figures were fairly frequent (a). Sinusoidal invasion was also observed (b). (H \& E, reduced from $200 \times$ ).

were considered to be in accordance with three of the nine criteria of Weiss [7].

Hypertension and hypokalemia improved to $120 / 78 \mathrm{mmHg}$ and $4.2 \mathrm{mEq} / \mathrm{L}$ within 2 weeks postoperatively. Basal levels and responses of PRA and PAC to furosemide also became normal, and the plasma cortisol level and excretion of UFC also showed normal response to DXM loading. The patient is alive with no evidence of disease 8 months after the operation. 
Table 3. Enzyme activity of the tumor

Activity of cytochrome P450s

\begin{tabular}{lccccc}
\hline & P450c17 & P450c21 & P450c11 & P450c18 & P450aldo \\
\hline Tumor & 0.48 & 1.72 & 0.86 & 0.03 & 0.040 \\
APA & $0.71-1.73$ & $3.36-9.82$ & $3.15-7.89$ & $0.25-0.428$ & $0.04-0.17$ \\
& $(1.37 \pm 0.38)$ & $(6.80 \pm 2.62)$ & $(5.29 \pm 2.14)$ & $(0.34 \pm 0.12)$ & $(0.125 \pm 0.05)$ \\
& & & & & \\
NA & $2.36-5.99$ & $1.58-4.68$ & $4.19-6.73$ & $0.28-0.41$ & UD \\
& $(3.67 \pm 0.78)$ & $(2.68 \pm 0.80)$ & $(5.72 \pm 0.94)$ & $(0.34 \pm 0.07)$ & UD \\
\hline
\end{tabular}

APA, aldosterone-producing adenoma; NA, normal adrenal; UD, undetectable. Data are shown as $\mathrm{nmol} / \mathrm{min} / \mathrm{mg}$ protein. Data on APA and NA were transferred from reference [8], and expressed as range (upper line) and mean \pm SD (lower line).

\section{Measurement of Steroidogenic Enzyme Activities}

Activities of cytochrome P-450c17 $\alpha$ and P-450c21 in the microsomal fraction of the tumor were measured in the presence of an NADPH-generating system using progesterone or 17-hydroxyprogesterone as the substrate [8]. Activities of mitochondrial P-450c11 $\beta$ and aldosteronesynthesizing enzyme (P-450aldo) were also measured using DOC as a substrate by the method reported previously [8]. As a control, data on P450s activity in normal control adrenals and APA were quoted from our previous report [9]. Although activities of all enzymes were detectable in the cancer tissue, activities of P-450c17 $\alpha$ and P450 c11 $\beta$ were definitely low, whereas that of $\mathrm{P}-450 \mathrm{c} 21$ was considerably preserved compared with that of normal adrenals and APA. On the other hand, the activity of P-450aldo which is usually undetectable in normal adrenal glands and adenomas other than APA was detectable as onethird of that of APA (Table 3).

\section{Discussion}

Aldosterone-producing adrenal cancer is a rare disease, and it accounts for only 4.0 to $7.2 \%$ of all adrenocortical cancers $[3,4]$, but aldosteroneproducing adrenal cancer without evidence of excess secretion of other steroids is uncommon, and the concurrent hypersecretion of glucocorticoid and/or androgen is frequently observed [10, 11]. Biochemical data which suggest excess secretion of glucocorticoid such as increased excretion of UFC and the level of plasma cortisol not suppressed by DXM, were also observed in the present case. The concurrent secretion of other steroids may indicate the malignant potential of the tumor if this finding was observed in cases with hyperaldosteronism [11, 12]. Plasma levels of other mineralocorticoids were not increased in the present case, but there are several reports of a concurrent increase in plasma corticosterone and DOC levels [11, 12]. Plasma and/or urinary steroid levels may correlate with the activity of steroidogenic enzymes and the bulk of the tumor, and from this point of view, the biochemical measurement of enzyme activities in the tumor may play a role in investigating the character of steroidogenesis. As the activity of P-450aldo is usually undetectable or extremely low in normal adrenal glands and adrenal adenomas other than APA, it was considered that this tumor could produce an excessive amount of aldosterone despite rather weak P-450aldo activity because the tumor weighed $100 \mathrm{~g}$. On the other hand, this tumor also could produce a rather excessive amount of cortisol due to the preserved P-450c21 activity even if activities of $\mathrm{P}-450 \mathrm{c} 17 \alpha$ and $\mathrm{P}$ $450 \mathrm{c} 11 \beta$ were reduced, but the hypersecretion of cortisol was not excessive enough to suppress plasma ACTH and to cause overt Cushing's syndrome. A suppressed plasma ACTH level was frequently observed in cases with benign adenomas causing Cushing's syndrome or preclinical Cushing's syndrome even if the production of cortisol was not excessive [13]. For this reason, some differences in sensitivity to ACTH may exist between adrenal cancers and benign adenomas. 
Histologically this tumor was in accordance with three of the nine criteria of Weiss: the mitotic rate, sinusoidal invasion and character of the cytoplasm. These pathological features were therefore considered to be compatible to those of nonmetastasizing/non-recurring adrenal cancer. Biochemical studies to evaluate enzyme activities in adrenal cancer have been conducted by a few workers, and a deficiency of P-450c11 $\beta$ or reduced activity of P-450c17 $\alpha$ were reported $[14,15]$. But these procedures can not demonstrate "which cells produce what steroids" as described by Sasano et al. [16]. They examined the localization of steroidogenic enzymes such as $\mathrm{P}-450 \mathrm{c} 17 \alpha$ and $\mathrm{P}-$ $450 \mathrm{c} 11 \beta$ at the cellular level immunohistochemically, and revealed that enzymes predominantly localize in small cancer cells with compact and/or clear cytoplasm, and with low grade nuclear atypia. As the positive staining of enzymes was observed focally, and a discrepancy between mRNA and protein expression of P$450 \mathrm{c} 17 \alpha$ was sometimes observed in adrenal cancer, they reported that the corticosteroidogenesis in adrenal cancer was considered to be ineffective [16]. Our biochemical data also suggested the character of steroidogenesis (inefficient steroidogenesis) in adrenal cancer, whereas the expression of P-450aldo activity was considered to be the specific character of this cancer for excessive secretion of aldosterone even if its activity was rather weak compared to that of APA. Although there have been a few reports in which steroidogenic activities were evaluated either by biochemical or immunohistochemical techniques, further precise studies in a large number of cases are needed to clarify and classify the steroidogenic characters of adrenal cancers.

\section{Acknowledgment}

Bovine adrenodoxin and NADPH-adrenodoxin reductase were generously donated by Dr. Fumiko Mitani of the Department of Biochemistry, School of Medicine, Keio University, Tokyo, Japan.

\section{References}

1. Ventakesh S, Hickey RC, Sellin RV, Fernandez JF, Samaan NA (1989) Adrenal cortical carcinoma. Cancer 64: 765-769.

2. Wooten MD, King DK (1993) Adrenal cortical carcinoma, Epidemiology and treatment with mitotane and a review of the literature. Cancer 72: 3145-3155.

3. Shimazaki J, Ichikawa T, Shiseki $Y$, Kuramochi $H$ (1993) Adrenal cortical carcinoma. Nihonrinsho 51(suppl): 766-782 (In Japanese).

4. Cohn K, Gottesman L, Brennan MF (1986) Adrenocortical carcinoma. Surgery 100: 1170-1177.

5. Kasperlik-Zaluska AA, Migdalska BM, Zgliczynski S, Makowska AM (1995) Adrenocortical carcinoma. A clinical study and treatment results of 52 patients. Cancer 75: 2587-2591.

6. Sullivan M, Boileau M, Hodges CV (1978) Adrenal cortical cancer. J Urol 120: 660-665.

7. Weiss LW (1984) Comparative histologic study of 43 metastasizing and nonmetastasizing adrenocortical cancer. Am J Surg Pathol 8: 163-169.

8. Morioka M, Ohashi $Y$, Watanabe H, Komatsu F, Jin T-X, Suyama B, Tanaka H (1997) ACTHindependent macronodular adrenocortical hyperplasia (AIMAH): Report of two cases and the analysis of steroidogenic activity in adrenal nodules.
Endocr J 44: 65-72.

9. Morioka M, Ohashi $Y$, Komatsu F, Tanimura M, Watanabe H, Jin T-X (1996) Adrenal adenoma in a patient maintained on chronic hemodialysis: A case report and analysis of steroidogenic activities. Endocrine Surgery 13: 309-313 (In Japanese).

10. Åberg H, Johansson H, Mörlin C, El-Sherief A (1981) Malignant aldosteronoma. A case report. Acta Chir Scand 147: 735-737.

11. Arteaga E, Biglieri EG, Kater CE, Lopez JM, Schambelan M (1984) Aldosterone-producing adrenocortical carcinoma. Preoperative recognition and course in three cases. Ann Intern Med 101: 316321.

12. Stone NN, Janoski A, Muakkassa W, Shpritz L (1984) Mineralocorticoid excess secondary to adrenal cortical carcinoma. J Urol 132: 962-965.

13. Morioka M, Ohashi $Y$, Komatsu F, Sawada K, Ebara S, Ohashi T, Kondo K (1996) Preclinical Cushing's syndrome: Report of four cases and analysis of steroid contents in adenomas. Horm Res 46: 117123.

14. Papadopoulos D, Gröndal S, Rydström J, DePierre JW (1992) Levels of cytochrome P-450, steroidogenesis and microsomal and cytosolic epoxide hydrolases in normal human adrenal tissue 
and corresponding tumors. Cancer Biochem Biophys 12: 283-291.

15. Naganuma $H$, Ojima $M$, Sasano $N$ (1988) $11 \beta$ hydroxylase in mitochondrial fractions of functioning and non-functioning adrenocortical tumors. Tohoku J Exp Med 155: 81-96.
16. Sasano H, Suzuki T, Nagura H, Nishikawa T (1993) Steroidogenesis in human adrenocortical carcinoma: Biochemical activities, immunohistochemistry, and in situ hybridization of steroidogenic enzymes and histopathologic study in nine cases. Hum Pathol 24: 397-404. 